\title{
Adjustable Intragastric Balloons: A 12-Month Pilot Trial in Endoscopic Weight Loss Management
}

\author{
Evzen Machytka • Pavel Klvana • Asher Kornbluth • Steven Peikin • \\ Lisbeth E. M. Mathus-Vliegen • Christopher Gostout • Gontrand Lopez-Nava • \\ Scott Shikora $\cdot$ Jeffrey Brooks
}

Published online: 8 May 2011

(C) The Author(s) 2011. This article is published with open access at Springerlink.com

\begin{abstract}
Intragastric balloons are associated with (1) early period intolerance, (2) diminished effect within 3-4 months, and (3) bowel obstruction risk mandating removal at 6 months. The introduction of an adjustable balloon could improve comfort and offer greater efficacy. A migration prevention function, safely enabling prolonged implantation, could improve efficacy and weight maintenance postextraction. The first implantations of an adjustable balloon with an attached migration prevention anchor are reported. The primary endpoint was the absence of bowel perforation, obstruction, or hemorrhage. Eighteen patients with mean BMI of 37.3 were implanted with the Spatz Adjustable Balloon system (ABS) for 12 months. Balloon volumes were adjusted for intolerance or weight loss
\end{abstract}

E. Machytka $\cdot$ P. Klvana

Faculty of Medicine, University of Ostrava,

Ostrava, Czech Republic

e-mail: evmac@seznam.cz

P. Klvana

e-mail: Pavel.klvana@fno.cz

A. Kornbluth

Mount Sinai Hospital,

New York, NY, USA

e-mail: Asher.kornbluth@gmail.com

S. Peikin

Robert Wood Johnson Medical School,

Camden, NJ, USA

e-mail: Peikinsteven@cooperhealth.edu

L. E. M. Mathus-Vliegen

Academic Medical Centre, University of Amsterdam,

Amsterdam, The Netherlands

e-mail: e.mathus-vliegen@amc.uva.nl plateau. Mean weight loss at 24 weeks was $15.6 \mathrm{~kg}$ with $26.4 \%$ EWL (percent of excess weight loss) and $24.4 \mathrm{~kg}$ with $48.8 \%$ EWL at 52 weeks. Sixteen adjustments were successfully performed. Six downward adjustments alleviated intolerance, yielding additional mean weight loss of $4.6 \mathrm{~kg}$. Ten upward adjustments for weight loss plateau yielded a mean additional weight loss of $7 \mathrm{~kg}$. Seven balloons were removed prematurely. Complications necessitating early removal included valve malfunction (1), gastritis (1), Mallory-Weiss tear (1), NSAID $(2 \times$ dose/ 2 weeks) perforating ulcer (1), and balloon deflation (1). Two incidents of catheter shear from the chain: one passed uneventfully and one caused an esophageal laceration without perforation during extraction. The Spatz ABS has

C. Gostout

Mayo Clinic,

Rochester, MN, USA

e-mail: Gostout.christopher@mayo.edu

G. Lopez-Nava

Hospital Universitario Madrid,

Sanchinarro, Spain

e-mail: glopeznava@digestivolopeznava.com

S. Shikora

Tufts Medical Center,

Boston, MA, USA

e-mail: sshikora@tuftsmedicalcenter.org

J. Brooks $(\square)$

Sheba Hospital,

Tel Aviv, Israel

e-mail: jeff@spatzmedical.net 
been successfully implanted in 18 patients. (1) Upward adjustments yielded additional weight loss. (2) Downward adjustments alleviated intolerance, with continued weight loss. (3) Preliminary 1-year implantation results are encouraging.

Keywords Intragastric balloon - Adjustable balloon . Inflation tube - "Holiday" period · Prolonged implantation . Weight loss

\section{Introduction}

There are 300 million obese in the world population, many of whom are in need of a medical device that will afford them significantly better results than current weight loss drugs and commercial weight loss systems. While severe technical failures led to the removal of weight loss balloons from the US market in 1985, the next generation intragastric balloons (IGBs) were totally redesigned and have been successfully used for the last 17 years outside of the USA. The published results reveal an average weight loss of $12-15 \mathrm{~kg}$ over 6 months [1-16]. Nevertheless, current generation IGBs have limitations; they have been associated with (1) deflation and bowel obstruction, (2) loss of effect after 2 to 3 months, (3) limitation to a 6-month implantation time, (4) significant nausea, vomiting, and discomfort in the early implantation period, necessitating balloon extraction in $4-7 \%$ of patients $[1,2],(5)$ balloon extraction requiring purchase of a dedicated tool, and (6) difficulty adjusting volume after implantation - technically, the Allergan balloon can be adjusted, but it is time consuming, tedious, impractical, and has essentially not been done for the last 17 years. The Endogast device is an air-filled balloon that is adjustable; however, it requires percutaneous anchoring to the abdominal wall, tunneling of the inflation tube subcutaneously by a surgeon, and reports a $12.2 \%$ subcutaneous infection rate [17].

The introduction of the Spatz Adjustable Balloon system (ABS) offers features that address these limitations. The aim of this first-in-man study is to report early safety and effectiveness results, and to encourage discussions as to how to best utilize this new generation IGB for chronic endoscopic weight loss management.

\section{Patients and Methods}

Following Ethics committee approval at the University Hospital in Ostrava, Czech Republic, a 6-month first-inman implantation study was undertaken in accordance with the ethical standards of the Helsinki Declaration of 1975, as revised in 2000. Patients were enrolled between October
2009 and March 2010. The primary endpoint was the absence of bowel obstruction, perforation, or significant hemorrhage. Additionally, weight loss at 12, 24, and 52 weeks and percent of excess weight loss (\% EWL) were also assessed.

The Spatz ABS (Spatz FGIA, Inc., NY, USA) was used in 18 patients, who were selected according to criteria used by currently CE Marked IGBs. Inclusion criteria included BMI $>27$ and those individuals in need of preoperative weight loss. Exclusion criteria were similar to the currently approved IGBs. Informed consent was obtained from all patients. Pre-implantation evaluation by a psychologist, dietician, and an experienced IGB endoscopist identified 18 patients appropriate for implantation. A binge eating scale was used to identify and exclude potential binge eaters. During the course of the study, the Ethics Committee approved extension of the implantation period to 12 months.

The Spatz ABS is composed of a silicone balloon that is mounted on a catheter on one surface. The catheter exits the balloon and has two loops that are perpendicular to each other, the larger of which has a metal chain that allows straightening of the curve, yet confers non-crushability (see Fig. 1). This non-collapsible loop maintains its $7-\mathrm{cm}$ diameter in the gastric lumen and is meant to prevent or delay a deflated balloon from passing through the pylorus and duodenum and evade endoscopic extraction. A highly visible white valve is connected to a stretchable inflation tube that exits the catheter. The stretchable inflation tube can be pulled out of the stomach with a snare, enabling balloon volume adjustability, while the balloon remains in the stomach. A highly visible blue clasp at the end of the catheter allows easy extraction with a standard polypectomy snare. Calibrations on the pusher identify device position during the implantation procedure. The device is straightened with a guidewire and is inserted similar to the passage of an oro-gastric tube, with the removal of the

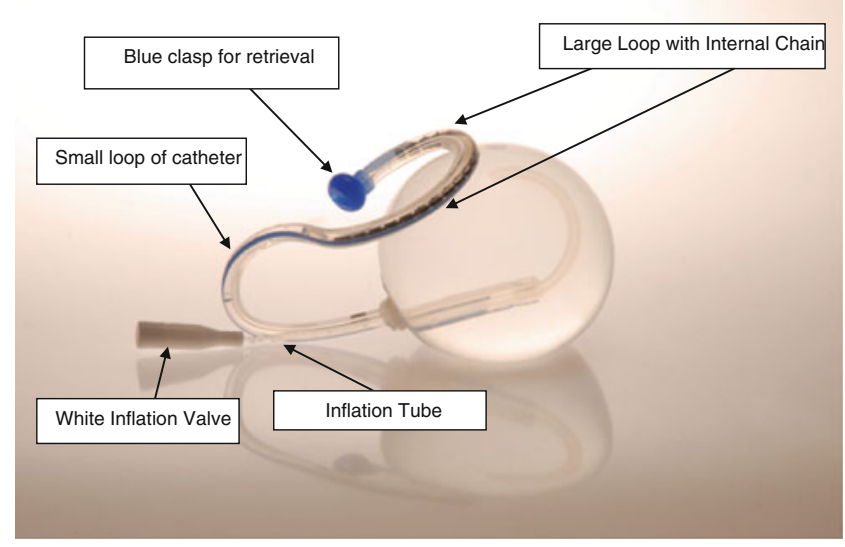

Fig. 1 Inflated balloon without stabilizer band (deployed state in gastric lumen) 
guidewire and pusher once the device passes the gastroesophageal junction. Generation 1 device was implanted in the first five patients (Figs. 1 and 2). Generation 2 device added a stabilizer band which maintained the larger loop in a closed position (Figs. 3 and 4). Thirteen patients were implanted with Generation 2 device. Balloons were deflated via the inflation valve or via needle catheter puncture, at the investigator's discretion. Devices were extracted with a standard polypectomy snare.

\section{Generation 2}

Eighteen patients ( 15 female, three male) with a mean BMI of 37.3 (range 29.4-53.2), a mean weight of $108.8 \mathrm{~kg}$ (range 89-163), a mean excess weight of $46.3 \mathrm{~kg}$ (range 26.8-73.6), and a mean age of 39 (range 21-57) were implanted with the Spatz ABS. Patients were followed up by a dietician and a gastroenterologist on a regular basis (weeks 1, 6, 12, 18, 24, $30,36,42,52$, and 60 with the principal investigator and/or dietician). The first five patients were implanted with Generation 1 device. After three of the first five patients had distal catheter tip migration into the duodenum, a stabilizer band was created to keep the large loop of the catheter closed. The next 13 patients were implanted with the Generation 2 device. None had distal catheter tip migration into the duodenum. One patient had the small loop migrate into the duodenum on day 14 which was pulled back into the stomach endoscopically, and has not recurred.

The Spatz ABS was implanted following a standard endoscopy under the sedation of an anesthesiologist. The first patient underwent general anesthesia, while the subsequent patients underwent conscious sedation using a narcotic, and midazolam, with or without propofol, at the anesthesiologist's discretion. The Spatz ABS was initially inflated with $400 \mathrm{ml}$ of sterile normal saline, with the exception of three patients that were inflated with 350,475 , and $500 \mathrm{ml}$, respectively. The initial protocol called for

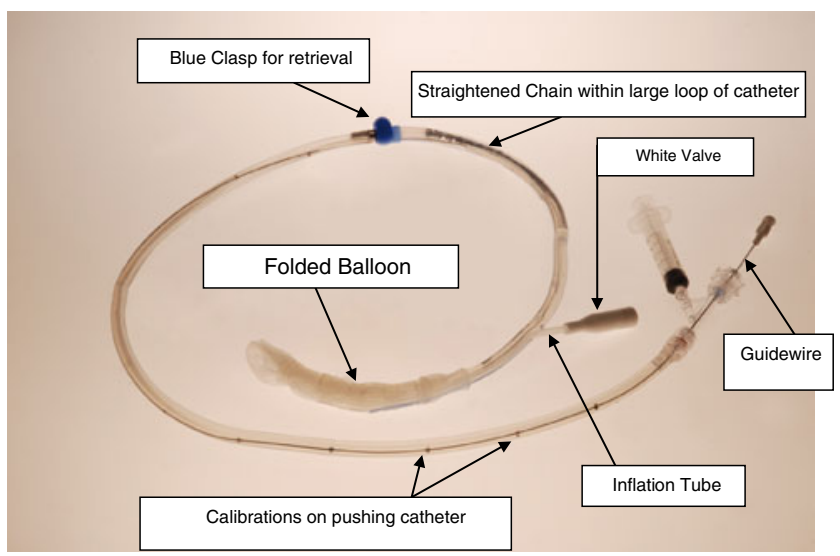

Fig. 2 Insertion assembly without stabilizer band

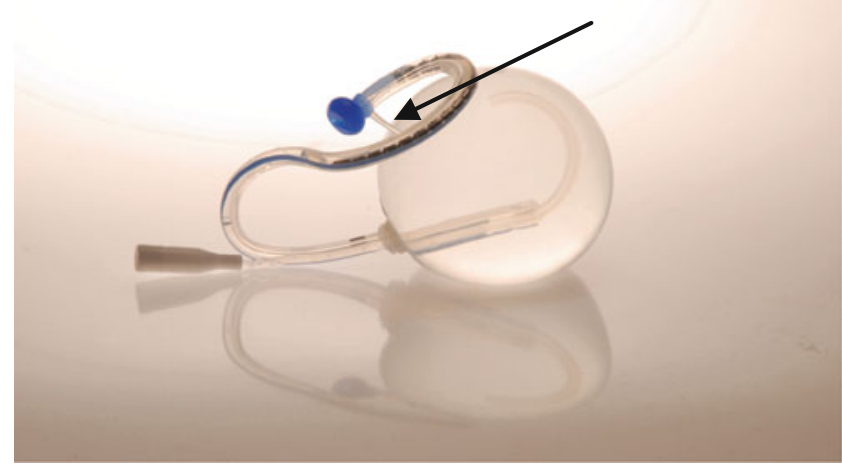

Fig. 3 Balloon with stabilizer band (arrow)

externalizing the inflation tube valve by leaving the extension tube out of the mouth and securing to the side of the mouth. The idea was to inflate or deflate the balloon $4 \mathrm{~h}$ after the procedure according to patient symptomshence, the three different volumes $(350,375$, and 500). The first three patients experienced discomfort when the valve was lowered back down the throat - the procedure was discontinued and the protocol was adjusted accordingly. The first five patients were observed overnight in the hospital, while the remaining patients were discharged on the day of the procedure. All patients were treated with Pantoprazole $40 \mathrm{mg}$ BID for 30 days followed by $40 \mathrm{mg}$ daily for the remainder of the implantation period. Antiemetics and analgesics were prescribed for the first 3 days post-implantation. All patients were discharged on clear liquid diet for 3 days, followed by a 1,000-kcal diet.

\section{Results}

The primary endpoint was met successfully by not having a single patient with a bowel obstruction, perforation, or significant hemorrhage. There were no deaths, and a single

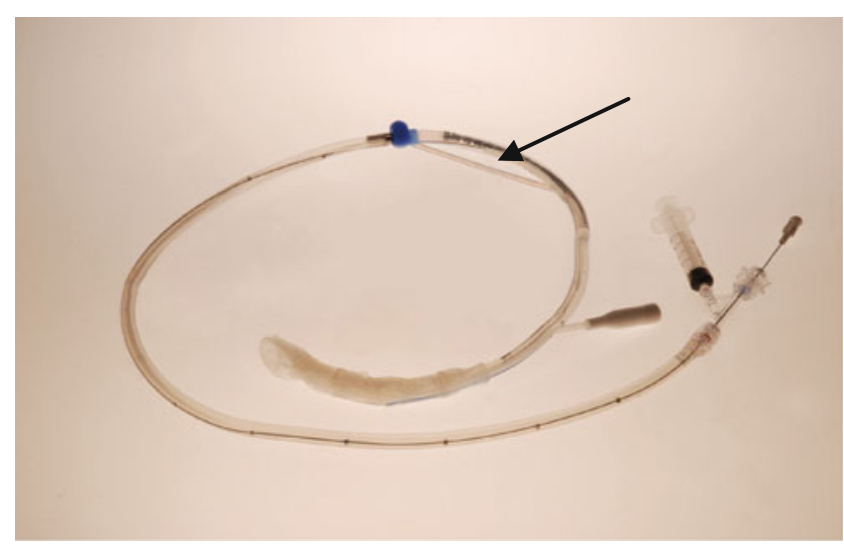

Fig. 4 Insertion assembly with stabilizer band (arrow) 
SAE (hospitalization) which was determined by the investigator to be unrelated to the IGB (patient no. 9 took double dose NSAID $\times 14$ days).

Implantation times varied from 20 to $60 \mathrm{~min}$ on the first five patients due to a floppy guidewire. Subsequent implantation times in the remaining 13 patients ranged from 8 to $15 \mathrm{~min}$.

Weight loss results are displayed in Table 1. Mean weight loss at 12 weeks was $11.1 \mathrm{~kg}$ with a $26 \%$ EWL. Mean weight loss at 24 weeks was $15.7 \mathrm{~kg}$ with a $36 \%$ EWL. Mean weight loss at 36 weeks was $20.4 \mathrm{~kg}$ with a $40.4 \%$ EWL. Mean weight loss at 52 weeks was $24.4 \mathrm{~kg}$ with a $48.8 \%$ EWL. Therefore, we also demonstrated that with the Spatz adjustable balloon, patients safely continue to lose weight beyond 6 months.

\section{Follow-Up Visit Compliance}

Follow-up visits with dietician and behavior modification experts have been shown to correlate with successful outcome [15]. We have defined successful outcome to be $>25 \%$ EWL. Table 2 shows the direct correlation.

\section{Adjustments}

The first adjustment was performed without endoscopic observation. This led to inflation tube kinking and tube rupture. The balloon was removed without any adverse event. The following 16 adjustments were performed successfully (Table 3). Six patients underwent downward adjustments with a mean volume of $117 \mathrm{ml}$. Intolerance was alleviated, and they continued to lose weight, with a mean additional weight loss of $4.6 \mathrm{~kg}$ after the adjustment. The other ten patients were adjusted upward for weight loss plateau, with a mean addition of $188 \mathrm{ml}$. Their mean additional weight loss following adjustment was $7 \mathrm{~kg}$.

\section{Comorbidities}

Improvements or stability of comorbidities are shown in Table 4.

\section{Adverse Events}

Patients experienced varying degrees of nausea, vomiting, and abdominal pain after implantation. Our data does not suggest any correlation between degree of post-implantation symptoms and successful outcome (defined as $>25 \%$ EWL). See Table 5.

Symptoms after adjustments were much lighter and better tolerated. See Table 6 .

Seven of the 18 balloons (39\%) were removed during the course of the study, as provided in detail in Table 7.

Patient no. 5 was noted to have moderate erosive gastritis at initial endoscopy, which, at the time was not deemed a contraindication to the implantation. Nausea and pain recurred at 6 weeks after implantation necessitating device removal. At explantation, the erosive gastritis had

Table 1 Weight loss

\begin{tabular}{|c|c|c|c|c|c|c|c|c|}
\hline \multirow[t]{2}{*}{$\mathrm{Pt}$} & \multirow[t]{2}{*}{ Device } & \multirow[t]{2}{*}{ BMI } & \multirow[t]{2}{*}{$\begin{array}{l}\text { Wt } \\
(\mathrm{kg})\end{array}$} & \multirow[t]{2}{*}{$\begin{array}{l}\text { Excess wt } \\
(\mathrm{kg})\end{array}$} & \multirow{2}{*}{$\begin{array}{l}\text { Weight loss }(\mathrm{kg}) / \% \\
\text { EWL } \\
\text { Week } 12\end{array}$} & \multirow{2}{*}{$\begin{array}{l}\text { Weight loss }(\mathrm{kg}) / \% \\
\text { EWL } \\
\text { Week } 24\end{array}$} & \multirow{2}{*}{$\begin{array}{l}\text { Weight loss }(\mathrm{kg}) / \% \\
\text { EWL } \\
\text { Week } 36\end{array}$} & \multirow{2}{*}{$\begin{array}{l}\text { Weight loss }(\mathrm{kg}) / \% \\
\text { EWL } \\
\text { Week } 52\end{array}$} \\
\hline & & & & & & & & \\
\hline 1 & Gen 1 & 39 & 135 & 57 & $11 \mathrm{~kg} / 19.3 \%$ & $12 \mathrm{~kg} / 21.1 \%$ & $16 \mathrm{~kg} / 28.1 \%$ & $20.5 \mathrm{~kg} / 35.1 \%$ \\
\hline 2 & Gen 1 & 42 & 115 & 53 & $19 \mathrm{~kg} / 35.8 \%$ & $28 \mathrm{~kg} / 52.8 \%$ & $34 \mathrm{~kg} / 64.2 \%$ & $45 \mathrm{~kg} / 85.4 \%$ \\
\hline 4 & Gen 1 & 36 & 123 & 50 & $20 \mathrm{~kg} / 40 \%$ & $30 \mathrm{~kg} / 60 \%$ & $35.5 \mathrm{~kg} / 71 \%$ & $41 \mathrm{~kg} / 82 \%$ \\
\hline 8 & Gen 2 & 37 & 99 & 37 & $10 \mathrm{~kg} / 27 \%$ & $18 \mathrm{~kg} / 48.6 \%$ & $23.5 \mathrm{~kg} / 63.9 \%$ & $32 \mathrm{~kg} / 86.5 \%$ \\
\hline 9 & Gen 2 & 32 & 98 & 30 & $7 \mathrm{~kg} / 23.3 \%$ & $9 \mathrm{~kg} / 30 \%$ & & \\
\hline 10 & Gen 2 & 33 & 89 & 28 & $11 \mathrm{~kg} / 39.3 \%$ & $14 \mathrm{~kg} / 50 \%$ & & \\
\hline 11 & Gen 2 & 41 & 110 & 48 & $10 \mathrm{~kg} / 20.8 \%$ & $13 \mathrm{~kg} / 27.1 \%$ & $19 \mathrm{~kg} / 39.8 \%$ & $29 \mathrm{~kg} / 60.4 \%$ \\
\hline 12 & Gen 2 & 33 & 98 & 33 & $5 \mathrm{~kg} / 15.2 \%$ & $8 \mathrm{~kg} / 24.2 \%$ & $6 \mathrm{~kg} / 18.3 \%$ & $3 \mathrm{~kg} / 9 \%$ \\
\hline 13 & Gen 2 & 29 & 74 & 16 & $7 \mathrm{~kg} / 43.8 \%$ & $8 \mathrm{~kg} / 50 \%$ & & \\
\hline 14 & Gen 2 & 39 & 117 & 47 & $14 \mathrm{~kg} / 29.8 \%$ & $20 \mathrm{~kg} / 42.6 \%$ & $22 \mathrm{~kg} / 47 \%$ & $15 \mathrm{~kg} / 32 \%$ \\
\hline 15 & Gen 2 & 44 & 135 & 67 & 13 kg/19.4\% & $20 \mathrm{~kg} / 29.9 \%$ & $29.5 \mathrm{~kg} / 43.8 \%$ & $30 \mathrm{~kg} / 45 \%$ \\
\hline 16 & Gen 2 & 51 & 133 & 74 & $10 \mathrm{~kg} / 13.5 \%$ & $9 \mathrm{~kg} / 12.2 \%$ & $5.5 \mathrm{~kg} / 8.2 \%$ & Lost to $\mathrm{f} / \mathrm{u}$ \\
\hline 17 & Gen 2 & 46 & 141 & 73 & $13 \mathrm{~kg} / 17.8 \%$ & $22 \mathrm{~kg} / 30.1 \%$ & $22 \mathrm{~kg} / 30.1 \%$ & $20 \mathrm{~kg} / 27.4 \%$ \\
\hline 18 & Gen 2 & 37 & 98 & 32 & $6 \mathrm{~kg} / 18.8 \%$ & $8 \mathrm{~kg} / 25 \%$ & $10 \mathrm{~kg} / 31 \%$ & $8 \mathrm{~kg} / 25 \%$ \\
\hline \multicolumn{5}{|c|}{ Mean } & $11.1 \mathrm{~kg} / 26 \%$ & $15.7 \mathrm{~kg} / 36 \%$ & $20.4 \mathrm{~kg} / 40 \%$ & $24.4 \mathrm{~kg} / 48.8 \%$ \\
\hline
\end{tabular}


Table 2 Compliance

\begin{tabular}{lll}
\hline Patients & Compliance & $\begin{array}{l}\text { Patients } \\
\text { with }>25 \% \\
\text { EWL }\end{array}$ \\
\hline $\begin{array}{l}2,3,4,5,6,7,8,10,11,13, \\
\begin{array}{l}14,15,18 \\
1,9,12,16,17\end{array}\end{array}$ & $\begin{array}{c}\text { Excellent (7); Very } \\
\text { good (6) }\end{array}$ & $10 / 13$ \\
\hline
\end{tabular}

Excellent $=$ attended all visits; Very good $=$ attended $>50 \%$ of visits; Fair $=$ attended $<50 \%$ of visits; Poor $=$ attended $<25 \%$ of visits

not healed in spite of Pantoprazole $40 \mathrm{mg}$ BID, and Helicobacter pylori infection was documented. Follow-up endoscopy 2 months later, after treatment for $H$. pylori infection, revealed complete healing of the gastritis.

Patient no. 3 had an adjustment for diminished weight loss. The inflation was performed without re-introducing the endoscope to observe for inflation tube kinking. The tube was kinked and burst, requiring balloon extraction. The patient tolerated the procedure without clinical event.

Patient no. 6 reported to the principal investigator a sensation of balloon deflation for 1 month. Endoscopy revealed a completely deflated balloon with the anchor in the stomach. The balloon was removed without clinical event.

Patient no. 13 had a Mallory-Weiss tear several days after an adjustment. The device was removed, and the patient was sent home the same day. The patient's hemoglobin was stable, and no additional clinical events were noted.

Patient no. 10 had a leak after her valve broke during her third adjustment procedure. The valve remained intact, connected to the balloon, but allowed a slow leak. The device was removed, and the patient was sent home the same day. The valve has two parts which were glued together. The two parts of the valve are now secured using heat welding.

Patient no. 9 took 2 weeks of Piroxicam $20 \mathrm{mg}$ daily plus three to four doses of Ibuprofen daily every day for low back pain. She then presented with a gastric perforation. At laparotomy, a NSAID-induced perforating gastric ulcer was oversewn. The device was noted to be intact, and the perforation was deemed to be a SAE from NSAID overdose. The patient was discharged and did well postoperatively.

The first three cases took 20-60 min to implant due to a floppy guidewire. After substituting a stiffer guidewire, the remaining implantations took 8 to $15 \mathrm{~min}$. Three patients with Generation 1 device (without the stabilizer band) had migration of the distal catheter into the duodenum. None with Generation 2 device had distal catheter migration. One patient with Generation 2 device (with stabilizer band) had passage of the small loop of the catheter into the duodenum. All four patients had the catheter pulled back to its normal position in the stomach and did not have a recurrence over the ensuing 20 or more weeks.

Table 3 Adjustments

\begin{tabular}{|c|c|c|c|c|c|c|}
\hline $\begin{array}{l}\text { Patient } \\
\text { no. }\end{array}$ & BMI & $\begin{array}{l}\text { Weight } \\
(\mathrm{kg})\end{array}$ & $\begin{array}{l}\text { Week of } \\
\text { adjustment }\end{array}$ & $\begin{array}{l}\text { Amount adjusted }(+/ \\
-) \mathrm{ml}\end{array}$ & $\begin{array}{l}\text { Weight lost prior to adjustment } \\
\text { (kg/week) }\end{array}$ & $\begin{array}{l}\text { Additional weight lost after adjustment } \\
\text { (kg/week) }\end{array}$ \\
\hline 1 & 39 & 135 & 26 & +200 & $13 \mathrm{~kg} / 26$ weeks & $7.5 \mathrm{~kg} / 26$ weeks \\
\hline 2 & 42 & 115 & 18 & +125 & $23 \mathrm{~kg} / 18$ weeks & $22 \mathrm{~kg} / 34$ weeks \\
\hline 4 & 36 & 123 & 20 & +150 & $25.5 \mathrm{~kg} / 20$ weeks & $10 \mathrm{~kg} / 13$ weeks \\
\hline 4 & & & 32 & -150 & $35.5 \mathrm{~kg} / 33$ weeks & $5.5 \mathrm{~kg} / 19$ weeks \\
\hline 9 & 32 & 98 & 10 & +200 & $4 \mathrm{~kg} / 10$ weeks & $5 \mathrm{~kg} / 14$ weeks \\
\hline 10 & 33 & 89 & 4 & -50 & $6.5 \mathrm{~kg} / 4$ weeks & $0.5 \mathrm{~kg} / 4$ weeks \\
\hline 10 & & & 9 & +150 & $7 \mathrm{~kg} / 8$ weeks & $7.5 \mathrm{~kg} / 16$ weeks \\
\hline 11 & 41 & 110 & 2 & -50 & $8 \mathrm{~kg} / 2$ weeks & $21 \mathrm{~kg} / 50$ weeks \\
\hline 12 & 33 & 98 & 13 & +150 & $4.5 \mathrm{~kg} / 13$ weeks & $3.5 \mathrm{~kg} / 11$ weeks \\
\hline 12 & & & & -150 & $8 \mathrm{~kg} / 24$ weeks & $+5 \mathrm{~kg} / 28$ weeks \\
\hline 14 & 39 & 117 & 1 & -100 & $6.8 \mathrm{~kg} / 1$ week & $8.2 \mathrm{~kg} / 51$ weeks \\
\hline 15 & 44 & 135 & 12 & +200 & $13 \mathrm{~kg} / 12$ weeks & $17 \mathrm{~kg} / 40$ weeks \\
\hline 16 & 51 & 133 & 24 & +300 & $8.5 \mathrm{~kg} / 24$ weeks & $+3 \mathrm{~kg} / 12$ weeks \\
\hline 18 & 37 & 98 & 14 & +200 & $6 \mathrm{~kg} / 14$ weeks & $2 \mathrm{~kg} / 38$ weeks \\
\hline 17 & 45 & 141 & 24 & -100 & $21 \mathrm{~kg} / 24$ weeks & $+1 \mathrm{~kg} / 28$ weeks \\
\hline \multirow[t]{4}{*}{13} & 29 & 74 & 24 & +200 & $8 \mathrm{~kg} / 24$ weeks & $\begin{array}{l}\text { Mallory-Weiss tear } 3 \text { days later. Balloon } \\
\text { removed }\end{array}$ \\
\hline & \multicolumn{6}{|c|}{ Upward adjustment yielded an additional $7 \mathrm{~kg}$ weight loss post-adjustment } \\
\hline & \multicolumn{6}{|c|}{ Downward adjustment alleviated intolerance and yielded additional $4.6 \mathrm{~kg}$ weight loss post-adjustment } \\
\hline & \multicolumn{6}{|c|}{ Adjustment procedure times ranged from 4-10 $\mathrm{min}$ and averaged $8 \mathrm{~min}$. All were done under conscious sedation. } \\
\hline
\end{tabular}


Table 4 Comorbidities

\begin{tabular}{llll}
\hline Patient no. & Comorbidity & Weight loss/Time & Comment \\
\hline 5 & Diabetes & $16 \mathrm{~kg} / 6$ months & $\begin{array}{l}\text { DM stable } \\
\text { BP Controlled }\end{array}$ \\
17 & Hypertension & $21.5 \mathrm{~kg} / 6$ months & HbA1c from 5.9 to 4.2 \\
3 & Diabetes & $24 \mathrm{~kg} / 6$ months & BP to $100 / 60$ Meds stopped \\
13 & Hypertension & $8 \mathrm{~kg} / 6$ months & BP controlled \\
\hline
\end{tabular}

Patient no. 3 passed a sheared catheter in her bowel movement uneventfully. The chain end cut through the wall of the catheter and caused a shearing of the catheter. The balloon remained intact in her stomach and was subsequently removed uneventfully. The patient experienced upper abdominal discomfort intermittently over a 2-day period, prior to passage of the catheter. During the extraction procedure of patient no. 11 , a deep laceration was noted in the proximal esophagus. The chain-end had sheared through the wall of the catheter (similar to patient no. 3) and scratched the esophagus during extraction. Barium swallow did not show an extravasation or perforation, but the surgeon elected to repair it surgically through a neck incision. She was discharged from the hospital 1 week later, without dysphagia.

Balloons were extracted by ensnaring the blue clasp with a polypectomy snare. During the course of this study, CE Mark was granted based on pre-clinical studies, literature review, technical file review, and preliminary results of this study. All engineering enhancements have been documented, verified, and validated according to the medical directive. As a result of the adverse events, several changes were made. (1) The IFU will stipulate "any erosive gastritis" as a contraindication. (2) A stretchable stabilizer band that spans the diameter of the large loop of the catheter was added. This keeps the catheter loop closed in the deployed position and resists opening of the loop, with the exception of insertion and extraction. (3) The metal chain will be curved and will have atraumatic ends surrounded by silicone glue to prevent catheter shearing. The addition of the stabilizer band also prevents catheter shear by preventing repetitive opening and closing of the loop. The catheter wall has now been reinforced with a strain relief band, as well. The catheter shear occurred on the radio-

Table 5 Post-implantation symptoms:

\begin{tabular}{lll}
\hline Patients & Severity & Patients with $>25 \%$ EWL \\
\hline $1,3,5,7,13,18$, & Mild & $4 / 6$ \\
$2,8,9,10,12,17$ & Moderate & $3 / 6$ \\
$4,6,11,14,15,16$ & Severe & $5 / 6$ \\
\hline
\end{tabular}

Mild $=<2$ days vomiting, and $<3$ vomits per day; Moderate $=2$ 5 days of vomiting or vomit up to $5 \times$ a day; Severe $=>6$ vomits/day or $>5$ days of vomiting opaque stripe on the catheter wall - its weakest point. The "stripe" will be eliminated since the metal chain makes the "stripe" superfluous. (4) To address the small loop migration into the duodenum, a second chain and stabilizer band were added to the smaller loop in a post-market release. This addition caused difficulty in guidewire release during insertion. Since the migration of the small loop occurred in only one of 18 patients in our study (without recurrence) and caused minor nausea and vomiting, the second chain and stabilizer band have thus been removed.

\section{Discussion}

Currently marketed IGBs, in their varying embodiments, are a static technology. The choice of balloon volume is made at the time of implantation - and is not easily changed. There is no way to gauge what size balloon is best for a specific patient, as the threshold for nausea vomiting and/or abdominal pain are not measurable or predictable. The loss of IGB efficacy after 3 months has been demonstrated convincingly in many studies $[3,16,18-22]$ and is considered a major drawback. This has led researchers to evaluate placement of a second balloon 1 month after removal of the first balloon. In a recent study, Lopez-Nava reported an additional drop of 2.6 points of BMI, following consecutive balloon placements in 112 patients [23]. In a similar study of consecutive BIB balloons, Genco reported a further drop of 3.9 points of BMI after the second balloon [24]. This upward adjustment was enacted using two consecutive "static" balloons-requiring two balloons and four endoscopic procedures. An adjustable balloon, on the other hand, offers dynamic bariatric therapy-requiring one balloon and three endoscopic procedures. Our study has shown the safety and efficacy of an adjustable balloon. Weight loss plateaus were treated with volume additions. Intolerance was successfully managed with a downward adjustment - patients regained their comfort, yet continued to lose weight. Both the downward and upward adjustments resulted in significant (4.6 and $8.1 \mathrm{~kg}$, respectively) weight loss following the adjustment.

IGBs carry a risk of migration of the deflated balloon and bowel obstruction. The largest BIB series reported 19 incidents of early gastric/duodenal obstruction. Eight occurred in partially deflated balloons which entered and 
Table 6 Post-adjustment symptoms

\begin{tabular}{lllll}
\hline Symptom & No. of episodes/day & Duration & Severity & $\%$ of patients w/symptom \\
\hline Nausea & & $1-2$ days & Mild & $20 \%$ \\
Vomiting & $1-2$ per day & $1-2$ days & Mild & $50 \%$ \\
Abdominal pain & 0 & 0 & 0 & $0 \%$ \\
\hline
\end{tabular}

blocked the pylorus. The other 11 obstructions occurred with normally inflated balloons and could not be explained by the authors [25]. We have encountered only one episode of spontaneous balloon deflation in one of our early implantations. The one episode of balloon deflation was rectified by additional adhesive between the catheter and the balloon edge. Our incidents of duodenal migration of our distal catheter tip in our first generation device have prompted the addition of the stabilizer band, which appears to have successfully prevented distal catheter tip migration. The addition of a stretchable stabilizer band that "closes the loop" of the "anchor" and exerts a force against the straightening of the "anchor" seems to prevent entrance into the duodenum. The combination of the internal chain (prevents collapse of the loop) and the stabilizer band (prevents opening of the loop) maintain the "anchor" in a $7-\mathrm{cm}$ diameter circle that hampers device migration in the event of balloon deflation-yet allows straightening for insertion and extraction.

Two critical reviews of IGBs have been reported in the literature, with similar overall positive results $[1,2]$. IGBs are an established successful weight loss therapy with 5,000 patients reported in the literature over the last 17 years [316]. Only a handful of studies report negative or equivocal results [26-28].Two randomized controlled trials (RCT) with crossover have been published [7, 29]. The Mathus-
Vliegen study found no difference in weight loss between sham and BIB groups in the first 13 weeks of the study. However, after crossover, the BIB group lost $4.9 \mathrm{~kg}$ more than the sham group [29]. In contrast, the Genco RCT with crossover study did show a $12 \mathrm{~kg}$ greater weight loss for the BIB over the sham group in the first half of the study. After crossover, again, the BIB group lost $7 \mathrm{~kg}$ more than the sham group [7]. The mechanism of action for weight loss with the IGB may be multifactorial. Aside from the obvious space occupying effect of IGBs, Ghrelin levels (an appetite enhancing hormone discovered in the stomach) have been documented to decrease during balloon implantation in one study [4] and uncorrelated in another study [26]. Prolonged gastric emptying has also been demonstrated during IGB implantation [4].

Over 100,000 IGBs have been implanted worldwide, with an impressive safety record and reproducible efficacy. Nonetheless, there remain issues and risks with current IGB technology.

Early nausea has been reported in every published BIB study. In one review, early balloon removal was reported in 143 out of 3,442 patients $(4.2 \%)$ in 13 of the articles reviewed [2]. In another review, early balloon removal was noted in $6.7 \%$, but if the 2,515 patients in the Genco study were added then these numbers are halved [1]. Given the lack of volume adjustability in current IGBs, endoscopists

Table 7 Device removals

\begin{tabular}{|c|c|c|c|c|}
\hline $\begin{array}{l}\text { Patient } \\
\text { no. }\end{array}$ & Event & $\begin{array}{l}\text { Week } \\
\text { no. }\end{array}$ & $\begin{array}{l}\text { Relation to device/ } \\
\text { procedure }\end{array}$ & Comment \\
\hline 7 & Pregnancy & 8 & Unrelated & Removed during second trimester \\
\hline 5 & $\begin{array}{l}\text { Erosive } \\
\text { gastritis }^{\mathrm{a}}\end{array}$ & 6 & Device related & $\begin{array}{l}\text { Patient implanted with mod-severe erosive } \\
\text { gastritis that did not heal } \\
\text { with PPI }\end{array}$ \\
\hline 3 & $\begin{array}{l}\text { Inflation tube } \\
\text { leak }^{\mathrm{a}}\end{array}$ & 8 & Procedural error & $\begin{array}{l}\text { First adjustment performed without } \\
\text { endoscopic observation }\end{array}$ \\
\hline 6 & Balloon leak $^{\mathrm{a}}$ & 18 & $\begin{array}{l}\text { Device related } \\
\text { malfunction }\end{array}$ & $\begin{array}{l}\text { Early generation device had insufficient } \\
\text { glue between balloon and catheter }\end{array}$ \\
\hline 13 & $\begin{array}{l}\text { Mallory- } \\
\text { Weiss tear }^{\mathrm{a}}\end{array}$ & 24 & Procedure related & Vomiting after adjustment \\
\hline 10 & Valve broke ${ }^{\mathrm{a}}$ & 28 & Device related & $\begin{array}{l}\text { Two parts of the valve bonded by glue } \\
\text { (newer model uses improved } \\
\text { heat bonding) }\end{array}$ \\
\hline 9 & $\begin{array}{l}\text { Gastric } \\
\text { perforation }^{\mathrm{a}}\end{array}$ & 28 & Unrelated & $\begin{array}{l}\text { Patient took double dose NSAIDS } \\
\text { (piroxicam and ibuprofen) } \times 14 \text { days } \\
\text { for low back pain }\end{array}$ \\
\hline
\end{tabular}

\footnotetext{
${ }^{\mathrm{a}}$ Discussions about each patient are explained in the text
} 
aim for the highest tolerated balloon volume, at the risk of greater nausea and vomiting and early balloon removal. The correct volume is an unknown for each patient. An adjustable balloon, however, can start with a smaller volume balloon with the expectation of increasing volume after two to 3 months (or when weight loss diminishes), offering a more comfortable early period. Although we only report our first 18 patients, their early period has been comfortable, with two of our patients (patient nos. 11 and 14) requesting downward adjustment to combat intolerance. They remained in the study and continued to lose weight. Only an adjustable balloon can offer this advantage.

The 2008 Mathus-Vliegen review reported a $3.3-8 \%$ balloon deflation rate within 6 months. She found that $25 \%$ of the deflated balloons remained in the gastric lumen; $71 \%$ passed harmlessly in the stool and $4 \%$ required surgery to alleviate bowel obstruction [1]. It is widely accepted and intuitively reasonable to assume that deflation rates increase with longer acid exposure. Intestinal obstruction has been reported with deflated balloons $[5,6,9,25,30-32]$, and as such IGB removal at 6 months is mandated. The Spatz balloon "anchor" enhances endoscopic retrieval of a deflated balloon and will diminish the risk of bowel obstruction. This in turn has allowed a longer 6-month implantation, granted by the CE Mark. Only one of our patients had a balloon leak. The patient reported this to us 1 month after sensing the deflation. Upon balloon retrieval, the anchor was noted sitting in the gastric antrum with the deflated balloon attached. Although it is only one episode, it does confirm the anchor function. Whereas our early generation device had distal catheter entry into the pylorus in three of five patients, it did not occur in the 13 patients that had a stabilizer band added in the Generation 2 device. If a Spatz balloon does deflate, and even if there is catheter entry into the pylorus, migration of the device and deflated balloon would be significantly hampered by the catheter, internal chain, and stabilizer band-allowing time for endoscopic retrieval. Deflation of the Allergan intragastric balloons have reported a $4 \%$ chance of bowel obstruction [1] - it cannot be studied, but it has been suggested that deflated balloons leave the stomach within hours and leave a very short window of opportunity for endoscopic retrieval. There is no safeguard for preventing migration - other than methylene blue causing a change in urine color. The Spatz balloon is the first intragastric balloon to attempt a mechanical means to prevent balloon migration.

Weight loss maintenance after balloon extraction has been reported with mixed results $[6,12,27,28,33]$. One year after IGB removal, patients regained $75 \%$ [27], 41\% [12], and $28 \%$ [28] of their lost weight. Crea reported a regain of three points of BMI 1 year after IGB removal; however, the maintenance of at least $10 \%$ of the body weight loss $\%$ was associated with an improvement in metabolic syndrome.
Negrin Dastis reported the maintenance of at least $10 \%$ weight loss in $24 \%$ of patients at 2.5 years post-balloon explantation [29].

IGB programs stress continued follow-up for behavior modification which has limited success in the postextraction period. Longer implantation times afford longer behavior modification times, which can presumably reap better weight loss maintenance results.

The overall function and safety of the device has been demonstrated in this pilot, first-in-man study. Although one balloon leaked and one valve malfunctioned (after third adjustment), these issues have been addressed with engineering enhancements. The presence of erosive gastritis has been shown to be a contraindication, as has been the use of NSAIDs. Our subject who double-dosed NSAIDs (Piroxicam and Ibuprofen) for 2 weeks developed a perforating NSAID ulcer-determined by the principal investigator to be unrelated to the device. One case of Mallory-Weiss tear after multiple bouts of vomiting is not unusual in this clinical setting. The episodes of catheter shear have been successfully addressed by engineering enhancements and will be reported in a forthcoming publication.

\section{The Future}

The introduction of an adjustable IGB with an attached "anchor" can potentially bring endoscopic "temporary" bariatric therapy to the level of endoscopic chronic weight management.

Our study is the first step towards changing the path of IGB therapy. The options are numerous. Sequential volume additions at every weight loss plateau, interspersed with 6 week "holidays" with a partially deflated balloon (to achieve a renewed effect), are now within our grasp. Trial of balloon deflation prior to extraction can identify potential relapsers (weight regain). The elimination of the obstruction risk by the "anchor" has allowed regulatory approval of 12 month implantation times. Longer implantation times afford greater weight loss, more effective behavior modification, and improved weight loss maintenance. Further studies will begin to tackle these questions. In the meantime, the technology has arrived.

Disclosures Dr. Jeffrey Brooks and Dr. Asher Kornbluth are shareholders in Spatz FGIA, Inc.

Conflicts of Interest Dr. Evžen Machytka, Dr. Pavel Klvana, Dr. Steven Peikin, Dr. L. Mathus-Vliegen, Dr. Christopher Gostout, Dr. Gontrand Lopez-Nava, and Dr. Scott Shikora have no conflict of interest. 
Open Access This article is distributed under the terms of the Creative Commons Attribution Noncommercial License which permits any noncommercial use, distribution, and reproduction in any medium, provided the original author(s) and source are credited.

\section{References}

1. Mathus-Vliegen EM. Intragastric balloon treatment for obesity: what does it really offer? Dig Dis. 2008;26(1):40-4. Epub 2008 Feb 15. Review.

2. Imaz I, Martínez-Cervell C, García-Alvarez EE, et al. Safety and effectiveness of the intragastric balloon for obesity. A meta-analysis. Obes Surg. 2008;18(7):841-6. Epub 2008 May 6. Review.

3. Bonazzi P, Petrelli MD, Lorenzini I, et al. Gastric emptying and intragastric balloon in obese patients. Eur Rev Med Pharmacol Sci. 2005;9(5 Suppl 1):15-21.

4. Mion F, Napoléon B, Roman S, et al. Effects of intragastric balloon on gastric emptying and plasma ghrelin levels in nonmorbid obese patients. Obes Surg. 2005;15(4):510-6.

5. Evans JD, Scott MH. Intragastric balloon in the treatment of patients with morbid obesity. Br J Surg. 2001;88(9):1245-8.

6. Sallet JA, Marchesini JB, Paiva DS, et al. Brazilian multicenter study of the intragastric balloon. Obes Surg. 2004;14(7):991-8.

7. Genco A, Cipriano M, Bacci V, et al. BioEnterics Intragastric Balloon (BIB): a short-term, double-blind, randomized, controlled, crossover study on weight reduction in morbidly obese patients. Int J Obes (Lond). 2006;30(1):129-33.

8. Doldi SB, Micheletto G, Perrini MN, et al. IGB; another option for treatment of obesity and morbid obesity. Hepatogastroenterology. 2004;51(55):294-7.

9. Roman S, Napoleon B, Mion F, et al. IGB for non-morbid obesity: a retrospective evaluation of tolerance and efficacy. Obes Surg. 2004;14(4):539-44.

10. Doldi SB, Micheletto G, Di Prisco F, et al. IGB in obese patients. Obes Surg. 2000;10(6):578-81.

11. Al-Momen A, El-Mogy I. IGB for obesity; a retrospective evaluation of tolerance and efficacy. Obes Surg. 2005;15(1):101-5.

12. Herve J, Wahlen CH, Schaeken A, et al. What becomes of patients 1 year after the IGB has been removed? Obes Surg. 2005;15 (6):864-70

13. Melissas J, Mouzas J, Filis D, et al. The IGB - smoothing the path to bariatric surgery. Obes Surg. 2006;16(7):897-902.

14. Busetto L, Segato G, De Luca M, et al. Preoperative weight loss by IGB in super obese patients treated with laparoscopic gastric banding: a case control study. Obes Surg. 2004;14(5):671-6.

15. Doldi SB, Micheletto G, Perrini MN, et al. Treatment of morbid obesity with IGB in association with diet. Obes Surg. 2002;12 (4):583-7.

16. Totte E, Hendrickx L, Pauwels M, et al. Weight reduction by means of an intragastric device; experience with BIB. Obes Surg. 2001;11(4):519-23.

17. Gaggiotti G, Tack J, Garrido Jr AB, et al. Adjustable totally implantable intragastric prosthesis (ATIIP)-Endogast for treatment of morbid obesity: one-year follow-up of a multicenter prospective clinical survey. Obes Surg. 2007;17(7):949-56.

18. Alfalah H, Philippe B, Ghazal F, et al. Intragastric balloon for preoperative weight reduction in candidates for laparoscopic gastric bypass with massive obesity. Obes Surg. 2006;16 (2): $147-50$

19. Vandenplas Y, Bollen P, De Langhe K, et al. Intragastric balloons in adolescents with morbid obesity. Eur J Gastroenterol Hepatol. 1999;11(3):243-5.

20. Al Kahtani K, Khan MQ, Helmy A, et al. Bio-enteric intragastric balloon in obese patients: a retrospective analysis of King Faisal Specialist Hospital experience. Obes Surg. 2010;20(9):1219-26.

21. Weiner R, Gutberlet H, Bockhorn H. Preparation of extremely obese patients for laparoscopic gastric banding by gastric balloon therapy. Obes surg. 1999;9:261-4.

22. Mui WL, Ng EK, Tsung BY, et al. Impact on obesity-related illnesses and quality of life following intragastric balloon. Obes Surg. 2010;20(8):1128-32.

23. Lopez-Nava G, Angel Rubio M, Prados S, et al. BioEnterics ${ }^{\circledR}$ intragastric balloon $\left(\mathrm{BIB}^{\circledR}\right)$. Single ambulatory Spanish experience with 714 consecutive patients treated with one or two consecutive balloons. Obes Surg. 2011;21(1):5-9.

24. Genco A, Cipriano M, Bacci V, et al. Intragastric balloon followed by diet vs. intragastric balloon followed by another balloon: a prospective study on 100 patients. Obes Surg. 2010;20(11):1496500 .

25. Genco A, Bruni T, Doldi SB, et al. Bio enterics intragastric balloon: the italian experience with 2,515 patients. Obes Surg. 2005;15(8):1161-4.

26. Martinez-Brocca MA, Belda O, Parejo J, et al. Intragastric balloon-induced satiety is not mediated by modification in fasting or postprandial plasma ghrelin levels in morbid obesity. Obes Surg. 2007;17(5):649-57.

27. Ganesh R, Rao AD, Baladas $\mathrm{HG}$, et al. The Bioenteric ${ }^{\circledR}$ Intragastric Balloon $\left(\mathrm{BIB}^{\circledR}\right)$ as a treatment for obesity: poor results in Asian patients. Singapore Med J. 2007;48(3):227.

28. Mathus-Vliegen EM, Tytgat GN. Intragastric balloon for treatment-resistant obesity: safety, tolerance, and efficacy of 1year balloon treatment followed by a 1-year balloon free follow up. Gastrointest Endosc. 2005;61:19-27.

29. Dastis NS, Francois E, Deviere J, et al. Intragastric balloon for weight loss: results in 100 individuals followed for at least 2.5 years. Endoscopy. 2009; 41:575-80.

30. Vanden Eynden F, Urbain P. Small intestine gastric balloon impaction treated by laparoscopic surgery. Obes Surg. 2001;11 (5):646-8.

31. Francica G, Giardiello C, Scarano F, et al. Ultrasound diagnosis of IGB complications in obese patients. Radiol Med (Torino). 2004; 108(4):380-4.

32. Kim WY, Kirkpatrick UJ, Moody AP, et al. Large bowel impaction by the BIB necessitating surgical intervention. Ann R Coll Surg Engl. 2000;82(3):202-4.

33. Crea N, Pata G, Della Casa D, et al. Improvement of metabolic syndrome following intragastric balloon: 1 year follow-up analysis. Obes Surg. 2009;19:1084-8. 